\title{
A Study on the Influence of Fuel Pipe on Fuel Injection Characteristics of Each Nozzle Hole in Diesel Injector
}

\author{
Fuqiang Luo ${ }^{1}$, Chuqiao Wang ${ }^{1}$, Fuying Xue ${ }^{1}$, Bingjian $\mathrm{Ye}^{1}$ and Xiwen $\mathrm{Wu}^{1,2}$ \\ ${ }^{1}$ Jiangsu University, China \\ ${ }^{2}$ Zhenjiang Watercraft College of PLA, China
}

\begin{abstract}
The inner diameter of high pressure fuel pipe has a significant effect on the fuel injection process and the performance of a diesel engine. The spray impact force of each nozzle hole of a conventional injection system of pump-line-nozzle for diesel engine (based on the spray momentum flux) and the injection pressure (on a fuel injection pump test rig) were measured. With varying fuel injection quantities and pump speed, the effects of the inner diameter of the high pressure fuel pipe on fuel injection process and the fuel injection characteristics of each nozzle hole were analyzed. It was noted from experimental results that the fuel injection pressure changes with variations in the inner diameter of the high pressure fuel pipe and also the injection duration gradually increases with increase in the inner diameter. .At low injection pump speed, even with the same geometric fuel deliver rate, the injection duration also increases gradually. Due to throttling effect and reduction in injection pressure, the fuel injection quantities of the injection nozzle were relatively minimal when the inner diameters of the high pressure fuel pipe were respectively small and large. The optimum injection pipe inner diameter for the right quantity for fuel injection falls between the two cases (between small and large). In addition, the injection rate of each nozzle hole increases with the decrease in angle between the needle axis and each of the nozzle hole axis. The fuel injection quantity of each nozzle hole increases while their relative difference decreases with increasing pump speed.
\end{abstract}

\section{Introduction}

The high-pressure fuel pipe, delivering the fuel from the injection pump to the injector, is an important part in diesel engines equipped with the conventional pump-line-nozzle fuel supply system. Hence, the fuel air interactions, fuel injection process and combustion process are all directly affected by the high-pressure fuel pipe. In other words, the fuel pipe has a direct influence on the performance of the engine [1]. Fuel flowing in the high pressure fuel pipe experiences complex hydraulic processes [2]. The expansion and contraction of the fuel pipe affects the transmission of pressure waves, which may lead to differences in the fuel delivery and injection starting points as well as the fuel supply rate and the injection rate. Improper sizing of the fuel pipe geometry (mainly inner diameter and length) causes distortion in injection rate resulting in abnormal injection phenomenon.

To understand the influence of the fuel pipe inner diameter on the injection characteristics of the injector, many experiments and techniques have been proposed in various literatures. The effects of the differences in fuel pipe geometric (length and inner diameter) on cylinder pressure and indicated power were studied in [3]. From [4], the relationship between the fuel injection advance angle and the start of fuel injection could be described by measuring vibration signals of high pressure fuel injection pipe in different cylinders. In addition, the fuel pressure fluctuations are affected significantly by the inner diameter and the length of the high pressure fuel pipe [5]. Mirko Bartatta [6] showed that fluctuations of the fuel injection quantities could be decreased by using an optimum length-diameter ratio of fuel pipe, and Bianchi $\mathrm{G} \mathrm{M}$ et al. [7] also demonstrated that the variations of the fuel injection quantities could be reduced by utlizing a short fuel pipe with large inner diameter. As reported in the reference [8], the influence of cavitation in the fuel pipe on the injection pressure and the injection rate was established together with and a validated measuring method for fuel injection rate.

Accurate measurements of total injection rate of the injector are obtainable by the methods proposed in the research outputs above, but not on the discrepancies in the injection rates among the various nozzle holes. It has been established from earlier literature that, the distribution of fuel pressure in accordance with the location of nozzle holes in a nozzle sac could be accurately calculated through simulations. The existence of cavitation during the injection process has also been established using validated simulations. However, since variations in fuel injection characteristics among nozzle holes were not studied within the literatures stated above, the differences exhibited between experimental and theoretical results could not be established.

The objective of this work is to investigate further, the 
discrepancies associated with fuel injection characteristics among nozzle holes. Firstly, the fuel pressure and the spray impact force of each nozzle holes were measured and the parameters of the fuel injection characteristics were computed based on the law of conservation of momentum and the momentum theorem. Secondly the fuel injection pressures, injection rates and cycle fuel injection quantities were analyzed under different fuel pipe inner diameters with respect to the variations of the pump cam rotational speed. And finally, a non-uniform coefficient of cycle fuel injection quantities within the nozzle holes is proposed with some optimization suggestions.

\section{Experimental set-up}

In order to study the fuel injection characteristics within each holes of the injection nozzle, a conventional fuel injection system of pump-line-nozzle was constructed on a fuel pump experimental bench. Injection rates were calculated by measuring the spray impact forces of each hole based on the spray momentum flux while the fuel injection pressures of injector were measured by calibrated piezoelectric sensor [9].

The experiment was performed with a $\mathrm{P}$ series injector with sac nozzle, as shown in Figure 1. It has five holes, with each hole diameter of $0.2 \mathrm{~mm}$ and an open pressure of $20 \mathrm{MPa}$. The length of the selected high pressure fuel pipes are $45 \mathrm{~mm}$, and their inner diameters are $1.6 \mathrm{~mm}, 1.8 \mathrm{~mm}, 2.0 \mathrm{~mm}$ and $2.5 \mathrm{~mm}$ respectively. For the experiment, a high pressure fuel pipe with inner diameter of $2.5 \mathrm{~mm}$ was selected; the fuel rack position was then adjusted to deliver a cycle fuel injection quantity of $51 \mathrm{~mm}^{3} \cdot \mathrm{cyc}^{-1}$ under the injection pump speed of $1000 \mathrm{r} / \mathrm{min}$. With the deliver fuel rack position fixed, the high pressure fuel pipes were replaced one after the other after measuring the fuel injection pressure of the injector and the spray impact forces of each nozzle hole, and at the injection pump speeds of $800 \mathrm{r} / \mathrm{min}, 1000 \mathrm{r} / \mathrm{min}$ and $1200 \mathrm{r} / \mathrm{min}$ respectively.
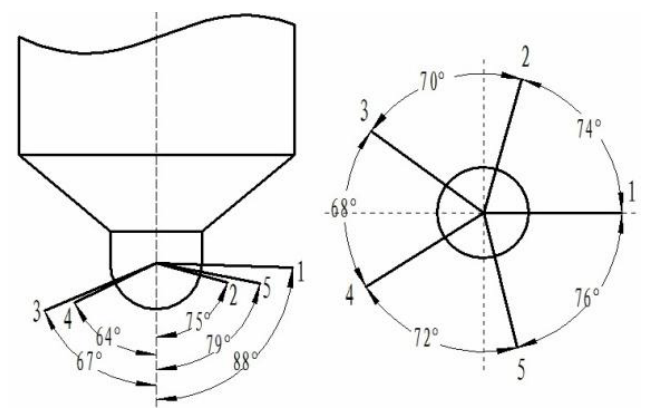

Figure 1. Schematic diagram of injection nozzle

\section{Experimental results and discussion}

\subsection{Variation of injection pressure}

The variations of injection pressure with the pump cam rotational angle at pump speeds of $800 \mathrm{r} / \mathrm{min}, 1000 \mathrm{r} / \mathrm{min}$ and $1200 \mathrm{r} / \mathrm{min}$ are shown in Figure 2 and Figure 3 respectively. Since the delivery fuel rack position was fixed during the experiment, the max-injection pressure of the different pipes changes with the change in injection pump speed. The fuel injection pressure, during the injection process increases rapidly whiles under the same injection pump speed, with corresponding increase in the fuel pressure due to the reduction in inner diameter. Increase in pump speed increases the max-injection pressure. This occurs because reduction in the inner diameter of the high pressure fuel pipe decreases the corresponding high pressure volume, hence resulting in reduction in the compression amount. The fuel injection pressures of all the four different pipes increases gradually with the increment of the injection pump speed due to the increase in the delivery fuel velocities of the plunger. The time for the units' cam rotational angle is decreased with increasing pump rotational speed [10]. Meanwhile, the residual fuel pressure for different inner diameters of the high pressure fuel pipes varies accordingly.

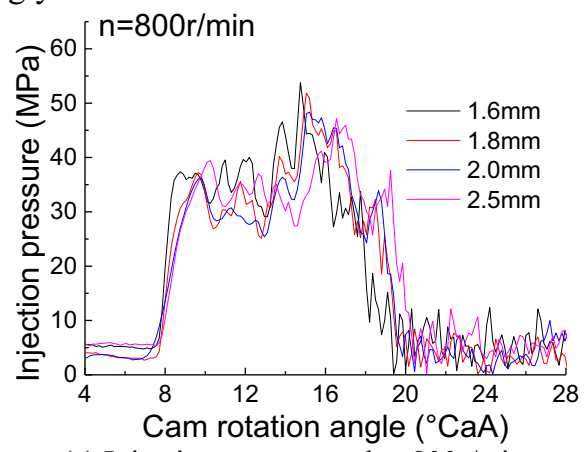

(a) Injection pump speed at $800 \mathrm{r} / \mathrm{min}$

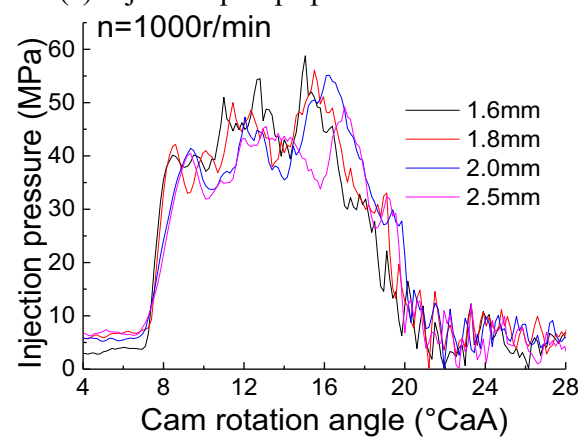

(b) Injection pump speed at $1000 \mathrm{r} / \mathrm{min}$

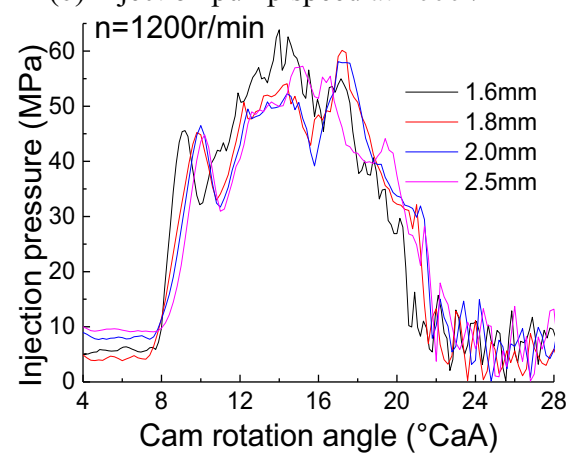

(c) Injection pump speed at $1200 \mathrm{r} / \mathrm{min}$

Figure 2. The injection pressures of different inner diameters fuel pipes of different pump speeds 


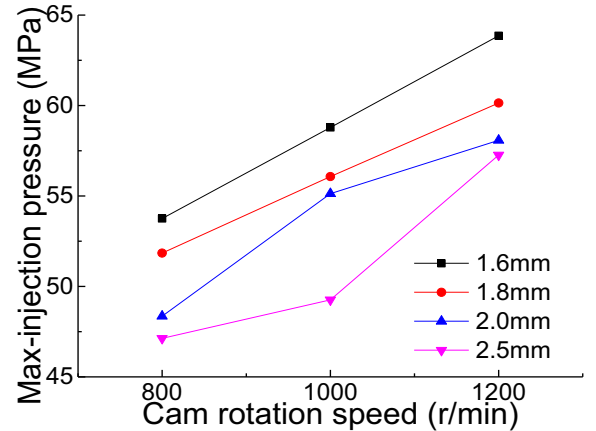

Figure 3. The variation of max-injection pressures for different inner diameters fuel pipes of different pump speeds

\subsection{Variation of injection rate}

The fuel injection process is affected directly by the variations in the fuel injection pressure. The variations of the transient injection rates of each nozzle hole, the pump cam rotational angle with different inner diameters of the high pressure fuel pipe and the injection pump speed are shown in Figure 4. For the same fuel pipe, the comprehensive curves of the injection rates of each nozzle hole are similar under the same injection pump speed. The cycle fuel injection quantities for each nozzle hole are uneven. The injection rate as well as the cycle fuel injection quantity are both decreased with the increment in angle between the nozzle hole axis and the needle axis $(\beta 4<\beta 3<\beta 2<\beta 5<\beta 1$, as shown in Figure 1). All the phenomena stated above are attributed to the deference in angle between the nozzle hole axis and the needle axis. The fuel flowing direction changes more with the increase in angle between nozzle hole axis and needle axis, leading to increases in flowing energy loss, thereby decreasing the spray impact force and the injection rate together with the cycle fuel injection quantity. Moreover, some differences are pronounced in the starting and ending phases of injection and also during the injection duration of each nozzle holes under the same pump rotational speed. This is mainly attributed to the difference in pressure distribution at the entrance of nozzle holes from the nozzle sac. When the nozzle hole is closed to the bottom of the nozzle sac, the relatively large pressure at the entrance, gradually advances the start and delays the end of the injection process by some degree with gradual increment in the fuel injection rate. [11].

The injection rate curve shapes of each nozzle holes vary with the inner diameters of the high pressure fuel pipes at the same injection pump speed. The variations in injection rate with the decrease in inner diameter of fuel pipe are mainly attributed to the difference in the fuel pressure rate resulting from the disparity of the high pressure volume. The injection rate curve profile tends to be steady with the increase of pump rotational speed, which is apparent when the high pressure fuel pipe inner diameter is $1.8 \mathrm{~mm}$. The injection rate curves are gradually transferred from the "boots" to the "rectangles", which follows the profile of the injection rate curve of the fuel injection system.
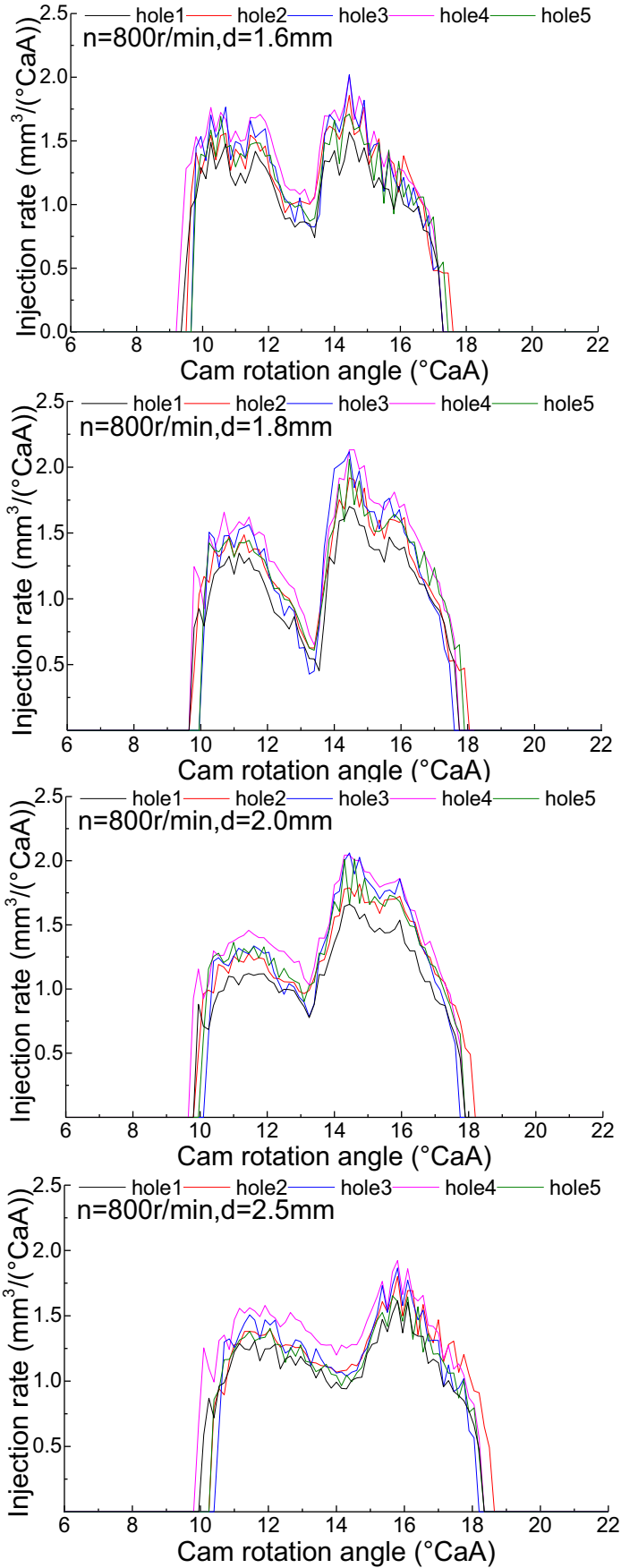

(a) Injection pump speed at $800 \mathrm{r} / \mathrm{min}$

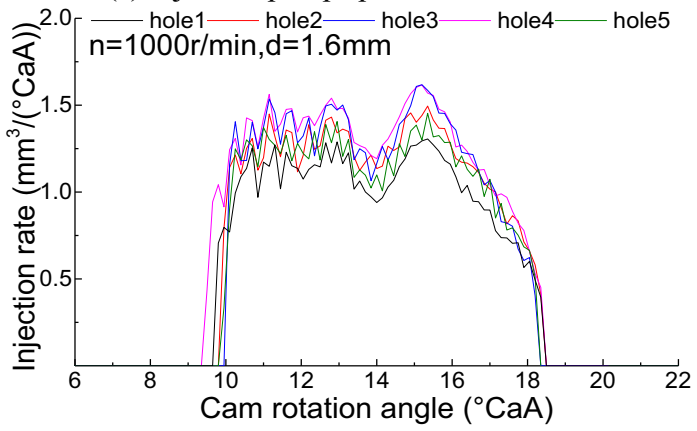



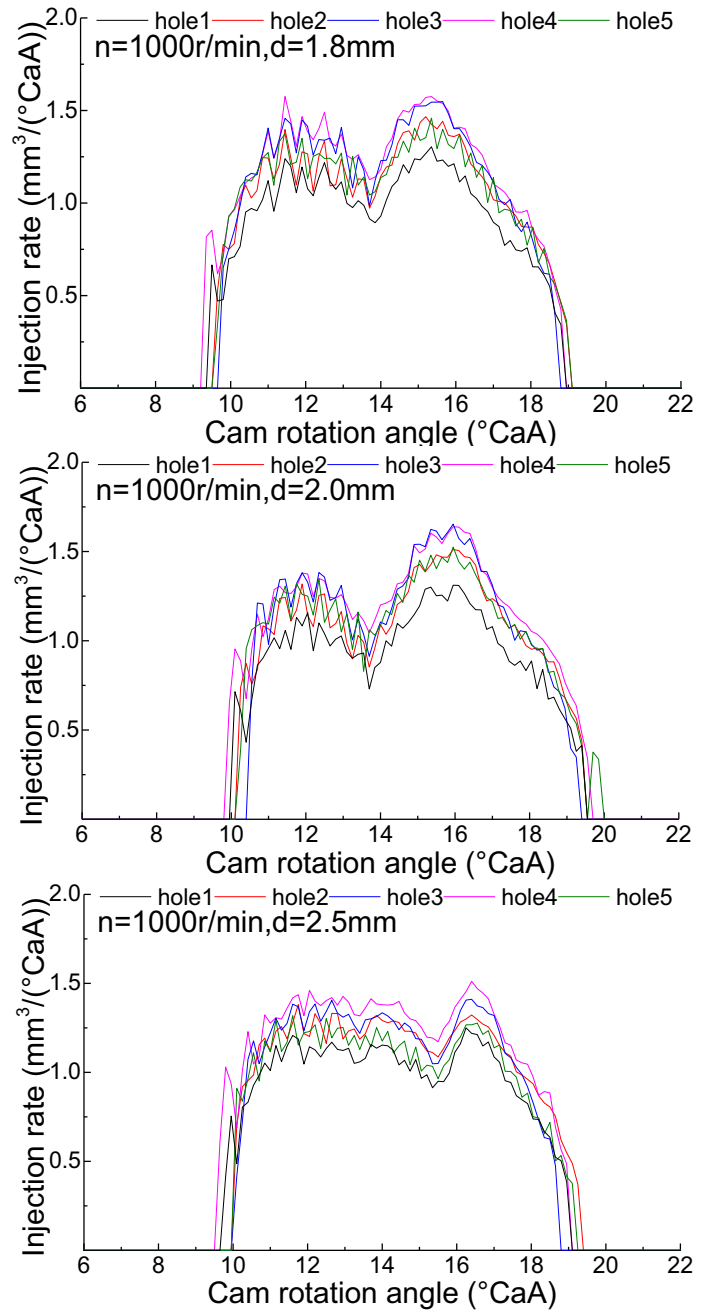

(b) Injection pump speed at $1000 \mathrm{r} / \mathrm{min}$
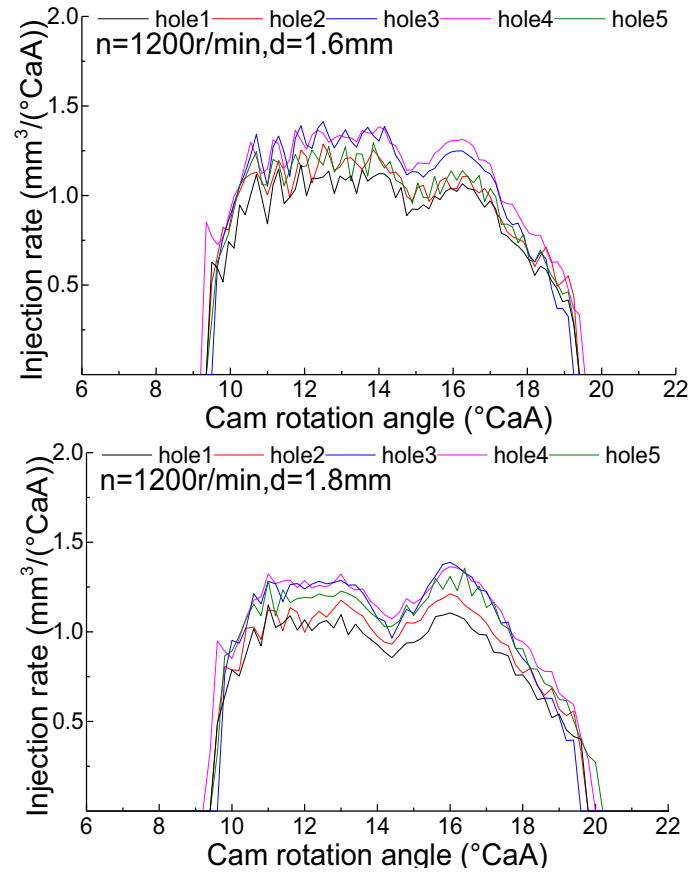
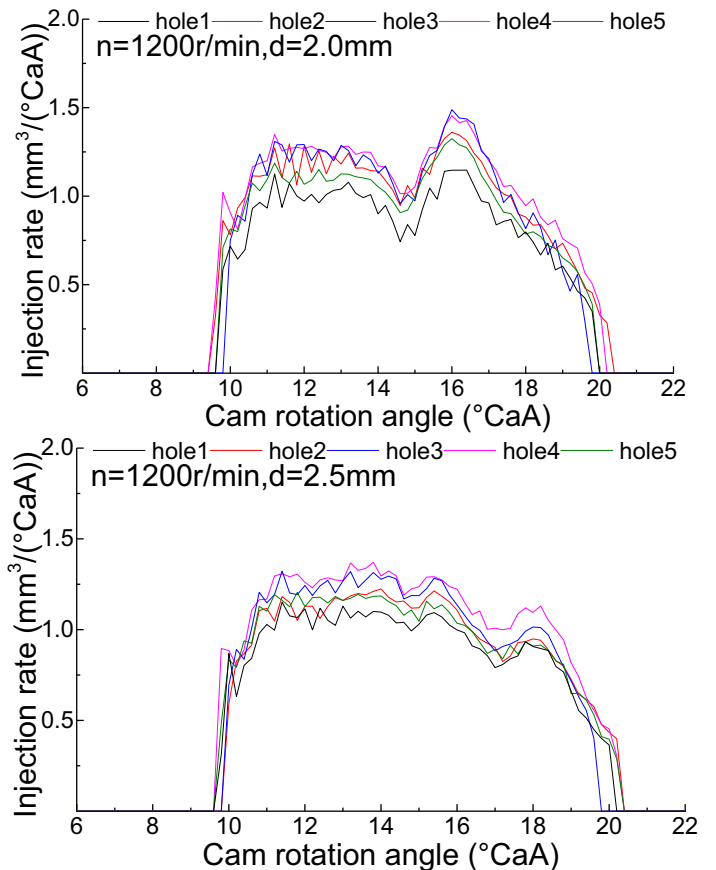

(c) Injection pump speed at $1200 \mathrm{r} / \mathrm{min}$

Figure 4. The injection rates of each nozzle hole for different inner diameters fuel pipes

The variations of the total injection rates of each nozzle hole with the change of the pump cam rotational angle under different pump rotational speeds for the four high pressure fuel pipe inner diameters are shown in Figure 5. It can be seen from the graphs that different inner diameters results in different total injection rate at the same injection pump speed. The injection rates curves are similar during the opening and closing phases of the needle, except the fully open phase of the needle lift. Significant difference exists between the fuel pipes with inner diameter of $2.5 \mathrm{~mm}$ and the rest of the pipes. This is mainly due to the increase in the inner diameter of fuel pipe which interns increases the high pressure volume, and the injection rate. At low injection pump speed, the fuel injection angle increases with the increment of the inner diameter of the high pressure fuel pipe. At high injection pump speed, the effect of the inner diameter of the different fuel pipe on the injection duration angle is minimal. This is because the fuel injection from the injector can be primarily regarded as a function of time, and the time characterized by the cam rotational angle, is decreased with increasing injection pump speed. In addition, when the inner diameter of the fuel pipe is 1.6 $\mathrm{mm}$, the injector needle drops prematurely, ending the advancement of injection and shortening the fuel injection duration. This is due to the fact that the smaller the inner diameter the higher the relatively fuel flow resistance and larger the quantity of energy loss due to the throttling effect. Moreover, gradual increments of the injection pump speed, advance the start and delays the end of the injection process by some degree. The injection rate during the injection period is decreased with its wave extension inclined toward flat graduation. Also, the total injection rate curve of each nozzle hole follows the same pattern as the fuel injection system, which is gradually changing from the "boots" to the "rectangles" [12]. 


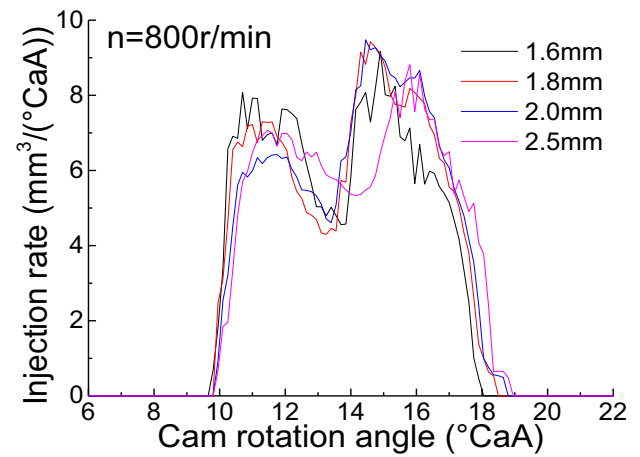

(a) Injection pump speed at $800 \mathrm{r} / \mathrm{min}$

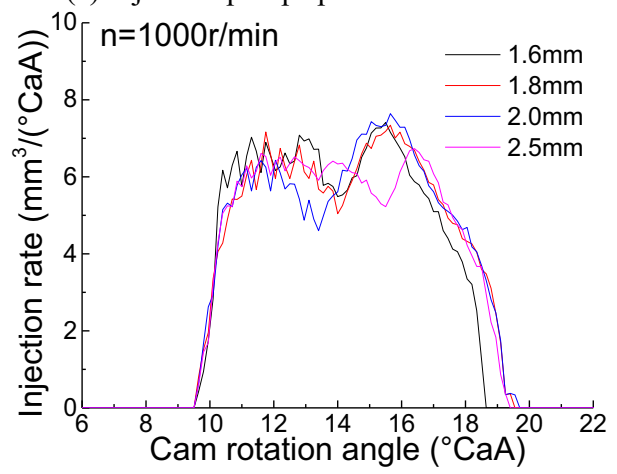

(b) Injection pump speed at $1000 \mathrm{r} / \mathrm{min}$

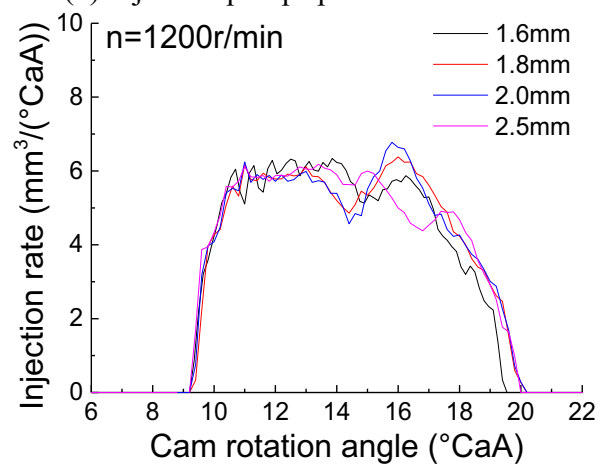

(c) Injection pump speed at $1200 \mathrm{r} / \mathrm{min}$

Figure 5. The injection rates of injection nozzle for fuel pipes of different inner diameters

\subsection{Variation of the cycle fuel injection quantities}

The variations of the cycle fuel injection quantities of each nozzle hole under different injection pump speeds for the four fuel pipes are shown in Figure 6. The cycle fuel injection quantities of each nozzle hole increases gradually with the injection pump speed irrespective of the inner diameter of the high pressure fuel pipe. This is largely attributed to the throttling effect and leakages. With the increase of injection pump speed, the throttling effect of the fuel return hole of the injection pump is improved while the leakages from the plunger and barrel assembly of the injection pump are decreased gradually. Additionally, for the same fuel pipe, the cycle fuel injection quantities of each nozzle hole are gradually decreased with the increase in the angle between the nozzle hole axis and the needle axis $\left(\beta_{4}<\beta_{3}<\beta_{2}<\beta_{5}<\beta_{1}\right.$, as shown in Figure 1) with the same injection pump speed. Hence, significantly higher is hole four and hole one is the least. This corresponds to the injection rate shown in Figure 4, which is the result of the discrepancies in flow characteristics of each nozzle hole due to layout parameters [13].

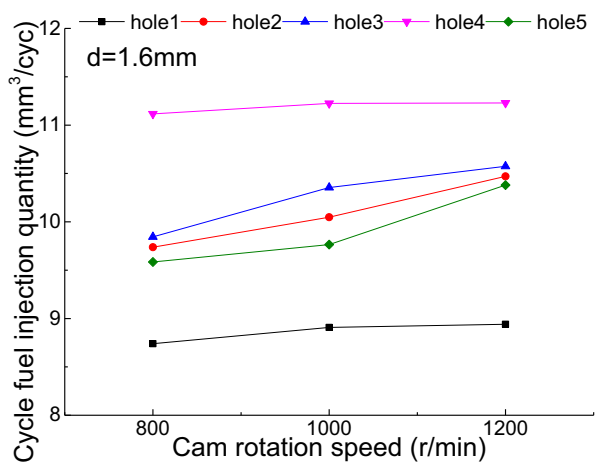

(a) $\mathrm{d}=1.6 \mathrm{~mm}$

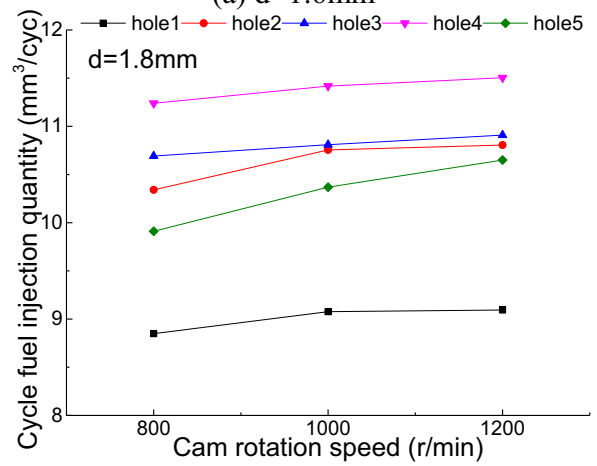

(b) $\mathrm{d}=1.8 \mathrm{~mm}$

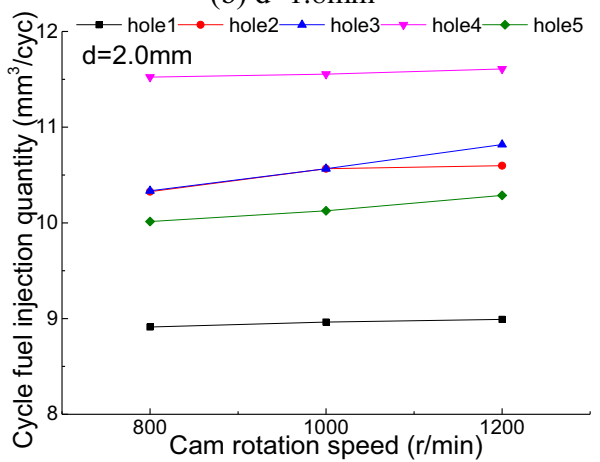

(c) $\mathrm{d}=2.0 \mathrm{~mm}$

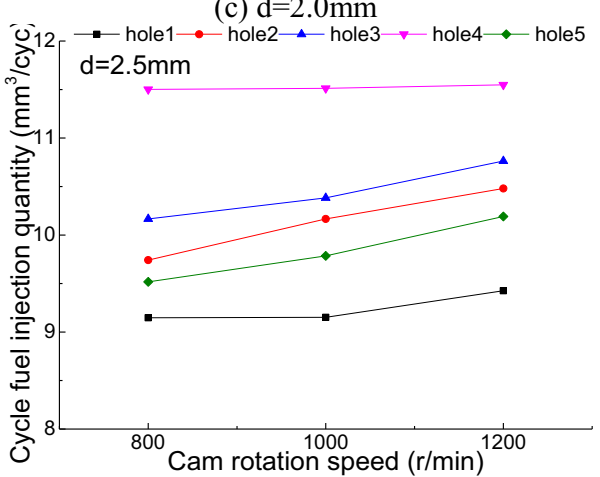

(d) $\mathrm{d}=2.5 \mathrm{~mm}$

Figure 6. The variations of cycle fuel injection quantities of each nozzle hole for different inner diameters fuel pipes with the change of injection pump speeds

In order to further understand the consistency among diesel nozzle holes under various working conditions, an evaluating parameter, $C_{n}$, (non-uniform coefficient of cyclical fuel injection quantities among nozzle holes) is defined [9]. It is the maximum difference of the fuel 
injection quantity within each hole divided by the mean value of the fuel injection quantity of each hole. Figure 7 shows the variation of the non-uniform coefficient of the cycle fuel injection quantities for each nozzle holes with the change in injection pump speed for different inner diameters of the high pressure fuel pipes. It can be seen from the graph that all non-uniform coefficients are above $21 \%$ and are all decreasing with the increment in injection pump speed. In addition, non-uniform coefficients of cycle fuel injection quantities among nozzle holes are different under different fuel pipes but with the same injection pump speed. This is relatively minimal when the inner diameter of fuel pipe is $1.8 \mathrm{~mm}$. The variations in the injection pressure characteristics due to the differences in the fuel pressure [14], are the main cause of this effect, as clearly evident in Figure 2.

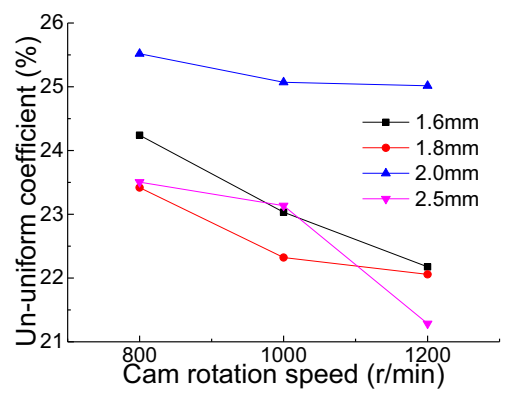

Figure 7. The variation of un-uniform coefficient of cycle injection quantity of each nozzle hole for different inner diameters fuel pipes with the change of pump speeds

Figure 8 gives the variations of the total cycle fuel injection quantity of the injector with the change in injection pump speed of different fuel pipes. From the figure, the total cycle fuel injection quantity of four different fuel pipes are all increasing with the increment in injection pump speed, but the rate of increase is different for the pipes. Under the same injection pump speed, the total cycle fuel injection quantities are different with different fuel pipe inner diameter. Specifically, when the inner diameter of the fuel pipe is $1.6 \mathrm{~mm}$, the cycle fuel injection quantity is the least, as shown in Figure. 5. Additionally, the cycle fuel injection quantities decrease with the increase of the inner diameter of the fuel pipe. This is mainly because of the increment of the high pressure volume due to the corresponding increase of the fuel pipes' inner diameter, and thus increases the compressible volume of fuel. In other words, the fuel injection quantity of the injection nozzle is at minimum when the inner diameter of the fuel pipe is either small or large due to the throttling effect and reduction in injection pressure respectfully. Hence the optimum value of the fuel injection quantity of the injection nozzle is obtained with a high pressure fuel pipe with a nominal inner diameter. For the systems analyzed in this paper, when the geometric fuel supply rate is invariant, the cycle fuel injection quantity of fuel pipe $(1.8 \mathrm{~mm}$ inner diameter $)$ is larger than the others by $1 \%-4 \%$ [15]. Considering the injection rate curves and power performances, the fuel pipe with the inner diameter $1.8 \mathrm{~mm}$ gives the optimum values.

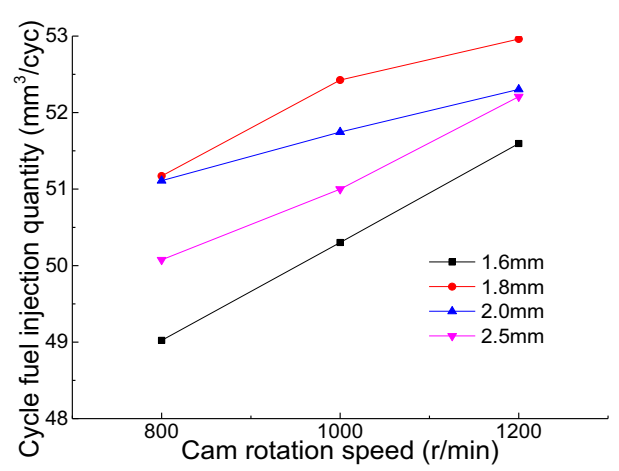

Figure 8. The variation of cycle fuel injection quantity of injection nozzle for different inner diameters fuel pipes with the change of pump speeds

\section{Conclusions}

In this paper, parameters of the fuel injection characteristic of the injection system of pump-line-nozzle for diesel engine with different inner diameters of high pressure fuel pipe under different operating conditions were measured and analyzed. The experimental results indicated that the fuel injection quantities of injection nozzle and the coefficient of fuel feeding are both relatively minimal when the inner diameter of the high pressure fuel pipe is either small or large due to the throttling effect and large trapped fuel volume respectfully, while fuel injection characteristics of each nozzle hole deteriorates. Hence, there is an optimum value for the injection pipe inner diameter of the fuel injection system, and the optimum parameter varies with different fuel injection system. For this system, the injection characteristic is comparatively optimal when the inner diameter of high pressure fuel pipe is $1.8 \mathrm{~mm}$. Other conclusions observed are as follows:

(1) With the increasing of the inner diameter of the high pressure fuel pipe, the comprehensive curves of the injection pressure exhibits fluctuation tendencies that reduces the fuel pressure.

(2) There are notable discrepancies in the curve profiles of the total injection rates of each nozzle holes with different inner diameters of the high pressure fuel pipes. The injection duration and the corresponding cycle fuel injection quantity are both decreased due to large energy losses from the throttling effect of small high pressure fuel pipe inner diameters.

(3) The injection rates as well as the cycle fuel injection quantities of each nozzle hole are both decreased with the increment of the angle between the nozzle holes axis and the needle axis. Besides, with the increment of injection pump speed, the cycle fuel injection quantities of each nozzle hole rises while their corresponding non-uniform coefficients drops.

\section{Acknowledgement}

This research was supported by the National Natural Science Foundation of China (No.51476072), Scientific Research Innovation Foundation for Graduate Students of Jiangsu Province (CXZZ12_0674) and a Project Funded 
by the Priority Academic Program Development of Jiangsu High Education Institutions.

\section{References}

1. C.C. Huang, S.J. Liu, B.F. Yin, et al., Small ICE. Moto. 1, 34(2012)

2. L.Y. Fan, Q. Li, X.Z. Ma, et al., Chin. ICE Eng. 6, 81(2013)

3. Hountalas D T, Anestis A., Energy Convers. Manage. 7, 587(1998)

4. Z.Q. Wang. Appl. Phys. Res. 2, 102(2009)

5. Catania A E, Ferrari A, Mittica A, et al., SAE Paper 1, 1258(2007)

6. Mirko B, Catania A E, Ferrari A. J. Fluids Eng. 12, 1(2008)

7. Bianchi G M, Falfari S, Brusiani F, et al., SAE Paper 1, 1236(2005)

8. Payri R, Salvador F J, Gimeno J, et al., Exp. Tech. 1, 46(2008)

9. F. Q. Luo, H. F. Cui, S.F. Dong, Fuel 6, 20(2014)

10. B.Q. Tian, L.Y. Fan, X.Z Ma, et al., Trans. Chin. Soc. Agri. Mach. 4, 1(2012)

11. X.L. Miao, J.B Zheng, J.H Hong., Trans. CSICE 5, 435(2012)

12. Benajes J, Molina S, De Rudder K, et al., J. Mech. Sci. Tech. 9, 1436(2006)

13. L.M. Shao, H.B Chang, J.D Zhou, et al., Chin. ICE Eng. 6, 43(2010)

14. Dernotte J, Hespel C, Foucher F, et al., Fuel 6, 153(2012)

15. L.Y. Fan, B.Q Tian, X.Z Ma, et al., Trans. Chin. Soc. Agri. Mach. 9, 14(2011) 